\title{
Robust projections of Fire Weather Index in the Mediterranean using Statistical Downscaling
}

\author{
J. Bedia · S. Herrera • D. San Martín • N. \\ Koutsias - J.M. Gutiérrez
}

Received: date / Accepted: date

\begin{abstract}
The effect of climate change on wildfires constitutes a serious concern in fire-prone regions with complex fire behavior such as the Mediterranean. The coarse resolution of future climate projections produced by General Circulation Models (GCMs) prevents their direct use in local climate change studies. Statistical downscaling techniques bridge this gap using empirical models that link the synoptic-scale variables from GCMs to the local variables of interest (using e.g. data from meteorological stations). In this paper, we investigate the application of statistical downscaling methods in the context of wildfire research, focusing in the Canadian Fire Weather Index (FWI), one of the most popular fire danger indices. We target on the Iberian Peninsula and Greece and use historical observations of the FWI meteorological drivers (temperature, humidity, wind and precipitation) in several local stations. In particular, we analyze the performance of the analog method, which is a convenient first choice for this problem since it guarantees physical and spatial consistency of the downscaled variables, regardless of their different statistical properties.

First we validate the method in perfect model conditions using ERA-Interim reanalysis data. Overall, not all variables are downscaled with the same accuracy, with the poorest results (with spatially averaged daily correlations below 0.5) obtained for wind, followed by precipitation. Consequently, those FWI components mostly relying on those parameters exhibit the poorest results. However, those deficiencies are compensated in the resulting FWI values due to the overall high performance of temperature and relative humidity.
\end{abstract}

S. Herrera · D. San-Martín

Predictia Intelligent Data Solutions, S.L., 39005, Santander, Spain

E-mail: sixto@predictia.es

J. Bedia · J.M. Gutiérrez

Instituto de Física de Cantabria, CSIC-Universidad de Cantabria, 39005 Santander, Spain

N. Koutsias

Department of Environmental and Natural Resources Management, University of Ioannina, GR-30100 Agrinio, Greece 
Then, we check the suitability of the method to downscale control projections (20C3M scenario) from a single GCM (the ECHAM5 model) and compute the downscaled future fire danger projections for the transient A1B scenario. In order to detect problems due to non-stationarities related to climate change, we compare the results with those obtained with a Regional Climate Model (RCM) driven by the same GCM. Although both statistical and dynamical projections exhibit a similar pattern of risk increment in the first half of the $21^{\text {st }}$ century, they diverge during the second half of the century. As a conclusion, we advocate caution in the use of projections for this last period, regardless of the regionalization technique applied.

Keywords fire danger $\cdot$ FWI $\cdot$ climate change $\cdot$ statistical downscaling $\cdot$ analog method

\section{Introduction}

Wildfires are highly dependent on a few meteorological drivers, which are able to reasonably explain fire activity at different scales, from local/regional (Pausas, 2004; Turco et al, 2012) to continental (Krawchuk et al, 2009) and to global (Pechony and Shindell, 2010). The potential effect of climate change in fire-prone regions is a serious concern, since the projected changes in climate extremes favor fire in many regions of the world (Groisman et al, 2007). Particularly, ecosystems in the Mediterranean are poor in biomass and rarely dry, so both fuel amount and fuel moisture limit the occurrence of large infrequent fires (Meyn et al, 2007). This has been confirmed for instance in Greece, where the synergistic effect between fuel and weather explained the unusually large wildfires in Peloponnese in 2007 (Koutsias et al, 2012).

The primary source of information for projecting fire danger conditions are the Global Climate Models (GCMs), which jointly simulate the global dynamics of the components of the climate system (including the atmosphere) for different future forcing/emission scenarios (Räisänen, 2007). However, several factors prevent the direct application of GCM outputs to local climate studies; in particular, their coarse horizontal resolution (hundreds of kilometers) is unable to represent local climate features. In order to bridge the gap between the large-scale variables provided by the GCMs and the local surface variables of interest (e.g. temperature, humidity, wind and precipitation), different downscaling techniques have been developed in the last decades. On the one hand, dynamical downscaling methods are based on Regional Climate Models (RCMs), which simulate regional features of the climate at a higher resolution over a limited area, driven at the boundaries by the GCM outputs (see e.g., Giorgi and Mearns, 1999). RCMs are physically consistent and provide a large number of variables describing the state of the atmosphere. However, the resulting regional biases need to be carefully considered, and to date there is no completely satisfactory bias-correction method for this task (Christensen et al, 2008; Maraun, 2012). On the other hand, statistical downscaling techniques are based on empirical statistical models linking the largescale variables, used as predictors, to the measured variables at the local scale, which become the dependent variable of the model (see e.g., Benestad et al, 2008). Statistical downscaling is computationally cheap and it is directly applicable to 
the local sites of interest, without need for further calibration or bias correction of the resulting outputs. However, this approach is limited to the variables and sites with available historical records. Thus, dynamical and statistical downscaling should be regarded as complementary tools whose effectiveness and applicability depend on the particular problem at hand.

In the framework of wildfire research, historical records of the driving meteorological variables are usually available at particular locations, representative of the fire regimes within the region of interest, often exhibiting complex topography and fire behaviors (e.g., Meyn et al, 2010) or intricated coastlines in the case of islands and coastal areas. Under these circumstances, the particular local climatic conditions may be poorly represented by RCM simulations. With this regard, statistical downscaling methods offer an a priori convenient alternative in order to locally project fire danger conditions. This approach is potentially useful in the Mediterranean, a fire-prone region of the world where most models predict warmer and drier conditions in the coming decades (Giorgi and Lionello, 2008). In this study we have chosen the Canadian Fire Weather Index (FWI, van Wagner, 1987) as a suitable and widely applied fire danger indicator, also in the context of future fire danger projections (Stocks et al, 1998; Brown et al, 2004; Flannigan et al, 2005; Moriondo et al, 2006). The suitability of this index as a fire danger indicator for different Mediterranean ecosystems has been already pointed-out by Viegas et al (1999) and Dimitrakopoulos et al (2011) among others. FWI uses as input the same variables as most other alternative fire danger indices — namely instantaneous values of temperature, relative humidity and wind speed at noon, or 12 UTC, and accumulated values of precipitation in the previous 24 hours (see Herrera et al, In press, for a detailed description) - , which are used to model the different factors involved in fire occurrence, spread and difficulty of suppression. It was therefore deemed as an appropriate index to illustrate the application of statistical downscaling in a variety of other wildfire research applications.

The main goal of this paper is analyzing the suitability of one of the most popular statistical downscaling methods (the analog method) for downscaling FWI values under future climate change scenarios on two Mediterranean fire-prone regions: the Iberian peninsula and Greece. The suitability of this methodology for wildfire applications has been already shown by Abatzoglou and Brown (2012), by comparing the skill to reproduce observations with that of advanced bias correction techniques, although to date, its application for future fire danger projections has not been specifically addressed. Besides its simplicity, a clear advantage of the analog method is that it provides physical and spatially coherent series for all the meteorological FWI drivers, regardless of their different statistical properties; on the other hand, its main shortcoming is that it can result unsuitable to address no-analog situations that may arise in a future climate, such as the medium to extreme warming conditions in the final decades of the $21^{\text {st }}$ century. We address a number of methodological issues relevant for the practical application of the analog method, such as the performance of different configurations of the method in "perfect model" conditions, using reanalysis data, or the problems related to nonstationarities. In addition, we illustrate its application in future climate conditions by considering transient projections from a single GCM (the IPCC-AR4/CMIP3 ECHAM5 model) and compare the results with those obtained with a Regional Climate Model (RCM) driven by the same GCM, in order to track the possible lack of robustness of the method in non-stationary conditions. In Sec. 2 we describe 
the data used in this work. Sec. 3 presents the statistical downscaling method (the analog method) and Section 4 describes the results obtained in present an future climate conditions, respectively, as well as the comparison with dynamical model results. Finally, Sec. 6 presents the conclusions of this work.

\section{Data and Geographical Domains}

In this paper we analyze two fire-prone Mediterranean areas (Iberia and Greece, Fig. 1), and consider data from observations, reanalysis and GCM global projections in order to compute and project the FWI in those regions. The following sections describe the particular datasets used.

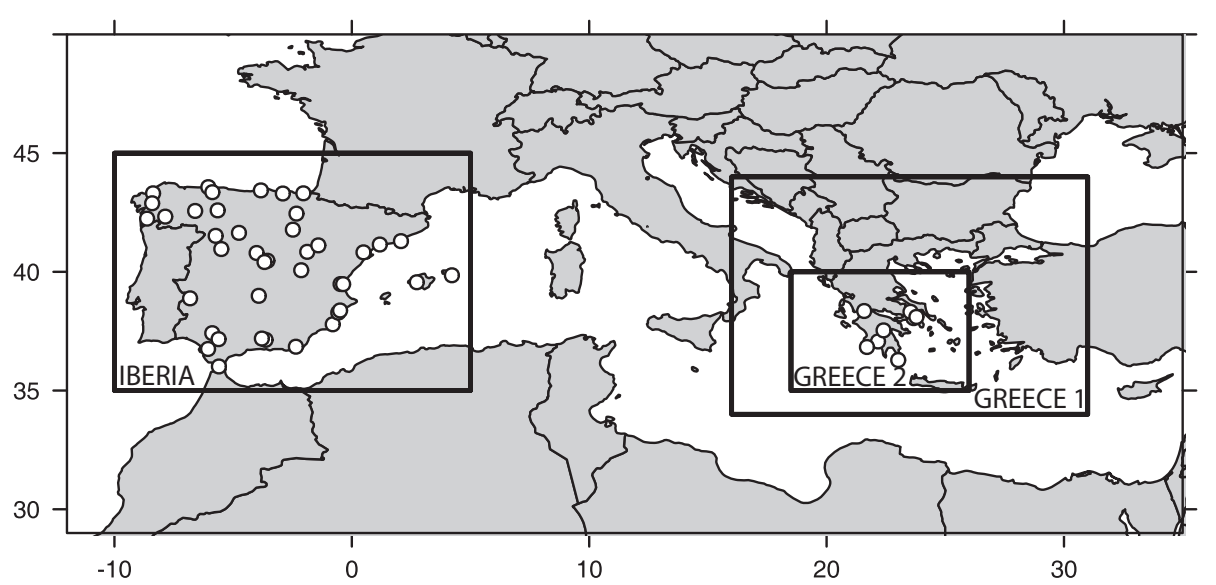

Fig. 1 The two domains used in this study, Iberia and Greece. The positions of the observation locations are indicated by the white circles. The two domains in Greece are used for sensitivity purposes in Sec. 4.

\subsection{Weather observations}

Local weather observations for Spain were obtained from 45 meteorological stations of the Spanish Meteorological Agency (AEMET), recording the required data for FWI calculation. The AEMET dataset provides instantaneous values of temperature, relative humidity and wind speed at 13 UTC, and accumulated values of precipitation in the previous 24 hours, recorded at 07 UTC. For the computation of FWI (see Sec. 2.2), the precipitation accumulated before noon is considered. Thus, we adjusted the AEMET precipitation by shifting one day ahead the whole precipitation series to match the dates of the rest of variables. As a result, it must be noted that, in the case of precipitation, there is a 5-hour lag between GCM/RCM and AEMET observations, whereas this lag is only 1 hour for the rest of variables. In summer local time, these measurements correspond to 15:00 (temperature, relative humidity and wind) and 09:00 (precipitation). 
The weather observations for Greece correspond to eight meteorological stations from the Hellenic National Meteorological Service (HNMS). The HNMS data have similar characteristics to the AEMET dataset, with the particularity that in this case instantaneous observations correspond to 09 UTC instead of 12 UTC, in order to better approximate UTC time with noon local standard time, provided that in Greece local time is one hour ahead than Spain. For Greece, high-quality observations could be only retrieved for the southern part of the country (Peloponnese and Attica regions).

Therefore, all observational data used in this study, both in Greece and in Iberia (Spain), correspond to the main station networks of their respective national meteorological services. All data have been recorded using standard automatic stations (the only ones providing records at short time-steps, allowing the extraction of noon values), and therefore data quality (outlier filtering, etc.) is guaranteed, as well as a missing data percentage always below $20 \%$. The resulting observed climatologies of the variables used to calculate FWI are displayed in Figure 2. It becomes apparent the high climate variability present in Iberia compared to Greece. The stations in northern Spain (northwestern Atlantic and north coast of the Cantabrian Sea) correspond to the Atlantic range of Spain, characterised by milder temperatures in summer and higher precipitation and relative humidity, leading to lower FWI magnitudes (Fig. 3). However, the rest of stations in central and Mediterranean coastal areas of Spain exhibit comparable climatologies than those found in Greece. Note that, in both study regions, the magnitudes of FWI during the fire danger season are significantly higher than in the annual case, but preserving a similar variability (Fig. 3).

\subsection{The Canadian Fire Weather Index (FWI) and derived components}

The FWI system is composed of six standard components (van Wagner, 1987). Three of them are known as "fuel moisture codes" and model daily changes in the moisture content of forest fuels with different drying rates depending on the nature of these materials: the fine fuel moisture code (FFMC), the duff moisture code (DMC), and the drought code (DC). One of the major strengths of the FWI system lies in these three moisture codes, which track moisture in three layers of the forest floor critical to fire ignition, spread and suppression (Wotton, 2009). The next two components are related to fuel consumption and fire spread: the build-up index (BUI) and the initial spread index (ISI). Finally, FWI is obtained as a combination of the previous parameters, representing the intensity of a spreading fire as energy output rate per unit length of fire front, which is used as a general, dimensionless, daily-based indicator of fire danger. Daily FWI values can be converted to a daily severity rating by applying a simple power transformation (DSR; van Wagner, 1970). This transformation allows the averaging of FWI over longer periods and takes into account the non-linear increase of fire severity with higher index values.

We computed FWI from the data shown in Sec. 2.1 (see also Fig. 2) following the original equations presented in van Wagner and Pickett (1985). For the time span experiment, we alternatively kept the whole annual time series and only the data corresponding to June-September (both included, in the following referred to as JJAS), thus focusing only in the season of critical fire danger over the target area, a common practice in fire danger analysis studies (e.g. Camia et al, 2008). 

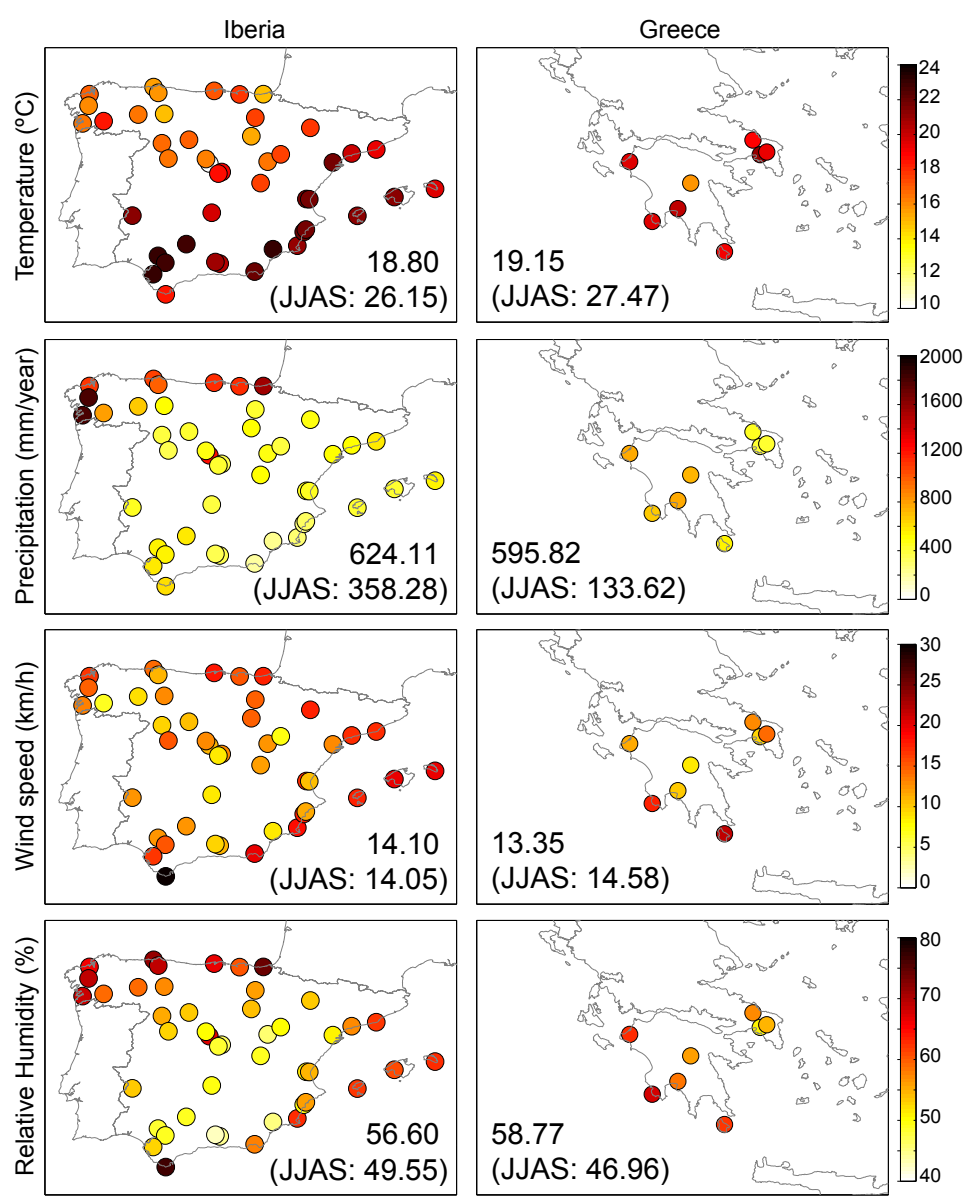

Fig. 2 Observed annual climatology (1979-2003) in Spain (left) and Greece (right) at the weather stations used for downscaling Fire Weather Index (FWI). The variables represented in rows correspond to the input variables used for FWI calculation. Spatial mean values (for the whole year and for the fire season - JJAS - , the latter in parenthesis) are indicated in the figures within each panel.

Fig. 3 shows the mean and standard deviation of the resulting FWI values for each of the periods. Moreover, we also computed two derived indices which are useful for practical applications:

- The seasonal severity rating (SSR), by averaging seasonally the DSR. This index is applied in many impact studies and fire prevention programs.

- The 90th percentile of FWI (FWI90), which is frequently used as an indicator of extreme fire danger situations (e.g., Andrews et al, 2003; Dowdy et al, 2010). 

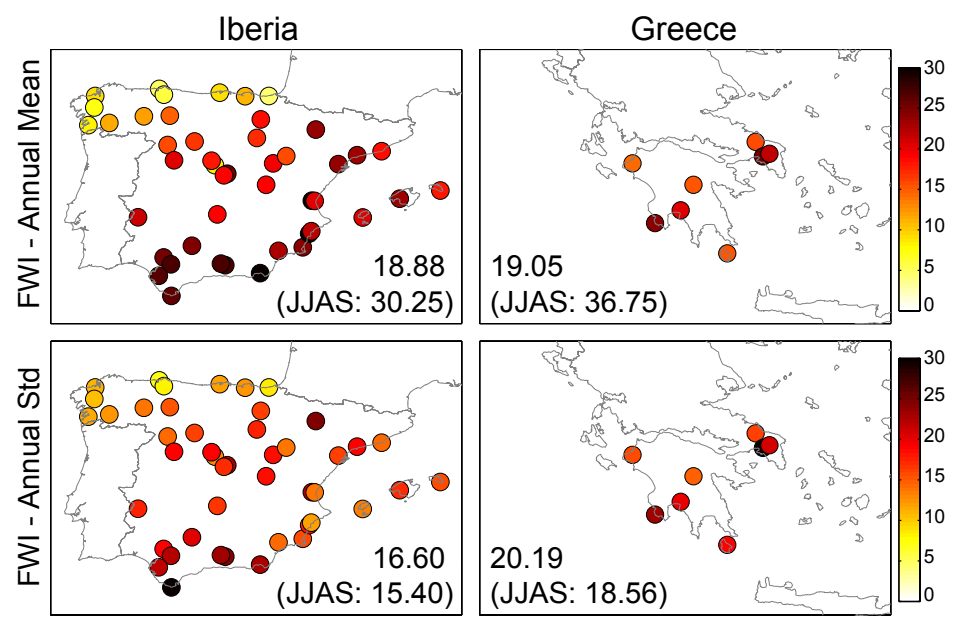

Fig. 3 Observed FWI climatologies (1979-2003) in Spain (left) and Greece (right) at the weather stations used for downscaling in this study. Values indicated in the panels correspond to spatial mean (upper panels) and standard deviation (lower panels), for the whole year and for the fire season - JJAS - (the latter in parenthesis).

\subsection{Reanalysis and GCM projections}

The different predictor variables tested in this study for the statistical downscaling method are shown in Table 1. On the one hand, predictors were taken from ERAInterim reanalysis (Dee et al, 2011), covering from 1979 until present; this product has proven the most suitable reanalysis for FWI estimation (Bedia et al, 2012). On the other hand, the same predictor variables were also taken from a single GCM (the IPCC-AR4/CMIP3 ECHAM5 model, run 3) for the control 20C3M scenario (1979-2000) and for the transient A1B scenario (whole $21^{\text {st }}$ century). Due to their different native horizontal resolutions, both reanalysis and GCM data were re-gridded - using bilinear interpolation - to a regular $2^{\circ}$ grid considering the domains shown in Fig. 1, following the standard practice in statistical downscaling applications. We considered 12 UTC in addition to 00 UTC and daily mean values, since FWI is calculated at noon. Regarding surface relative humidity, this was calculated from the surface temperature and the dew point, following the classical Clausius-Clapeyron equation (Lawrence, 2005).

Note that in this paper we do not intend to provide final products regarding future FWI projections over the regions of interest, but only to assess the suitability of the analog methodology for this task. Therefore, for illustrative purposes we used a single GCM, although in a different context a multi-model ensemble approach should be considered, accounting for the variability of different GCM projections.

Finally, it is worth to remark that all the predictors considered (Table 1) are well reproduced in southwestern Europe by most of the GCMs used in the EUfunded project ENSEMBLES (van der Linden and Mitchell, 2009) after bias removal (Brands et al, 2011) and, in particular, by the ECHAM5 model used in this study. 
Table 1 Predictor variables used in this work. 3D variables contain information at the 850 and $500 \mathrm{hPa}$ levels. $2 \mathrm{D}$ variables refer to mean sea level.

\begin{tabular}{lllll}
\hline Code & Name & level & time & unit \\
\hline $\mathrm{T}$ & Temperature & 3D & $12 / 00 \mathrm{UTC}$ & $\mathrm{K}$ \\
$\mathrm{R}$ & Relative humidity & 3D & $12 / 00 \mathrm{UTC}$ & $\%$ \\
$\mathrm{U}$ & U-wind & 3D & $12 / 00 \mathrm{UTC}$ & $\mathrm{ms}^{-1}$ \\
$\mathrm{~V}$ & V-wind & 3D & $12 / 00 \mathrm{UTC}$ & $\mathrm{ms}^{-1}$ \\
$\mathrm{SLP}$ & Sea-level pressure & 2D & daily mean & $\mathrm{Pa}$ \\
$2 \mathrm{~T}$ & Surface (2m) Temperature & 2D & daily mean & $\mathrm{K}$ \\
$\mathrm{R}$ & Surface Relative humidity & 2D & daily mean & $\%$ \\
10U & 10m U-wind & 2D & daily mean & $\mathrm{ms}^{-1}$ \\
10V & 10m V-wind & 2D & daily mean & $\mathrm{ms}^{-1}$ \\
\hline
\end{tabular}

\section{The Analog Downscaling Method}

The analog method was introduced in the field of atmospheric science by Lorenz (1969). It is a simple and powerful downscaling technique which assumes that similar (or analog) atmospheric patterns $\boldsymbol{X}$ over a given region lead to similar local meteorological outcomes $\boldsymbol{Y}_{s}$ for a particular location or set of locations $s$ $(\boldsymbol{Y}=\{$ temperature, humidity, wind, precipitation $\}$ in this study; note that boldface is used for vectors). This assumption provides a simple algorithm to downscale the local occurrence of the variables of interest $\boldsymbol{Y}_{s i}$ from a given atmospheric pattern $\boldsymbol{X}_{i}$ (e.g. from the $i$-th daily projection of a GCM). The local occurrence is estimated from the historical daily occurrences $\boldsymbol{Y}_{s} \boldsymbol{a}(i)$ in a set of "analog dates" $\boldsymbol{a}(i)$ within a historical calibration period (1979-2003 in this study). Under the perfect prognosis approach (hereafter referred to as "perfect model" conditions), the atmospheric patterns in the calibration period are built using a reanalysis dataset and, hence, the analog dates correspond to those historical days with atmospheric reanalysis patterns closer to $\boldsymbol{X}_{i}$. In particular, we applied the deterministic nearest neighbor method (Zorita et al, 1995; Cubasch et al, 1996; Gutiérrez et al, 2013), by which only the closest analog (in the sense of the Euclidean distance) is considered. Then, $\boldsymbol{Y}_{s i}=\boldsymbol{Y}_{s a(i)}$ and, hence, both the spatial and inter-variable (or physical) dependence structure of the observational data is preserved in the downscaled series. Thus, apart from its simplicity, the main advantage of the analog method is that it can be jointly applied to all the local variables in all the local sites needed for the FWI calculation.

In general, it has been shown that the analog method performs as well as other more sophisticated downscaling techniques (Zorita and von Storch, 1999), indicating that this poor-man method is an efficient alternative for many downscaling problems. In particular, a complex variant of the analog method, the so-called multivariate adapted constructed analogs, has been successfully applied to wildfire research (Abatzoglou and Brown, 2012), outperforming the skill of advanced bias correction techniques to reproduce local observations. However, this methodology suffers from several problems which may limit its application in non-stationary future climate change conditions (Benestad et al, 2008), particularly in the medium to extreme warming conditions predicted for the second half of the $21^{\text {st }}$ century (Gutiérrez et al, 2013). This issue is of special relevance in fire research, given that the fire danger season corresponds to summer, when new temperature maxima are predicted to occur in the future, being extreme FWI events linked to exceptionally 
warm periods (see e.g., Bedia et al, 2012, and Fig. 2 therein). In the following we focus in this challenging problem, and analyze the suitability of the simple analog method for downscaling FWI values under future climate change scenarios.

The difficult step in the configuration of the analog method is the appropriate definition of the atmospheric pattern $\boldsymbol{X}$ - defined by a geographical domain and a set of large-scale variables - suitable to downscale the local variables of interest. In this paper, we build on the results obtained in the Spanish national program on regional scenarios Escenarios-PNACC 2012 (Gutiérrez et al, 2012). In this project, different geographical domains and predictor sets were compared over the Iberian peninsula in order to asses the performance of different downscaling methods (see Gutiérrez et al, 2013, for the results for temperature). The optimum results found for temperature and precipitation in both Atlantic and Mediterranean climatic regions were achieved with the smallest geographical window considered: a window centered on the Iberian Peninsula with bounding box coordinates $45^{\circ} \mathrm{N}, 35^{\circ} \mathrm{N}$, $10^{\circ} \mathrm{W}$, and $5^{\circ} \mathrm{E}$ (Fig. 1). In the case of Greece, we considered a geographical domain of the same area, but centered over the area of study (labeled as Greece 1 in Fig. 1: $44^{\circ} \mathrm{N}, 34^{\circ} \mathrm{N}, 31^{\circ} \mathrm{E}, 16^{\circ} \mathrm{E}$ ), and tested the sensitivity of the downscaling results to the window size and position, following a similar procedure as in Gutiérrez et al (2013). In this case, due to the smaller area covered by the observations (Peloponnese and Attica regions) we considered also a smaller domain covering the network of stations $\left(40^{\circ} \mathrm{N}, 35^{\circ} \mathrm{N}, 26.0^{\circ} \mathrm{E}, 18.5^{\circ} \mathrm{E}\right)$, labelled as Greece 2 in Fig. 1. Similarly to the case of Iberia, the best results were obtained with the domain Greece 1. Thus, in the following we only report the results for the Greece 1 domain.

The different predictors tested in this study (Table 1) include the typical variables used in the statistical downscaling studies carried out for different European regions (see e.g. Maraun et al, 2010; Gutiérrez et al, 2013, and references therein). The predictor combinations were chosen to meet the needs of fire danger climate change studies, and in particular of FWI, and include "signal-bearing" predictors (e.g. temperature) in order to capture a potential climate change signal (Table 2). Pattern P1 is defined based on the variables involved in the calculation of FWI, considering their values in the middle troposphere, since surface variables are not properly represented by GCMs due to their coarse orography; as the only exception we also consider $2 \mathrm{~m}$ temperature, since near surface temperature has been found to be the optimum predictor for temperatures in several studies (see Gutiérrez et al, 2013, and references therein). The surface version of P1 (pattern P2) is considered only for benchmarking purposes in "perfect model" conditions. Other alternative configurations were also tested (patterns P3 and P4), attaining no significant improvements (not shown).

Moreover, for every predictor combination, two static definitions were set, considering the values at $12 \mathrm{UTC}$ and $00 \mathrm{UTC}$, respectively. In addition, a dynamic pattern was also considered, joining both 00 and 12 UTC values in the same pattern for downscaling. Similar results were obtained in all cases. Therefore, we selected the static pattern at $00 \mathrm{UTC}$, since this output is available in the ENSEMBLES GCMs used in Sec. 5, whereas the 12 UTC was not available. 
Table 2 Predictor combinations selected for statistical downscaling. For each combination, both the static (12 and 00 UTC) and dynamic (00+24 UTC) temporal setup have been tested. Variable names are indicated in Table 1.

\begin{tabular}{llllll}
\hline Pattern & \multicolumn{5}{l}{ Variables } \\
P1 & $2 \mathrm{~T}$ & $\mathrm{~T} 850$ & $\mathrm{R} 850$ & $\mathrm{U} 850$ & V850 \\
P2 & $2 \mathrm{~T}$ & 2R & 10U & $10 \mathrm{~V}$ & \\
P3 & 2T & R850 & & & \\
P4 & SLP & T850 & U500 & V500 & Q850 \\
\hline
\end{tabular}
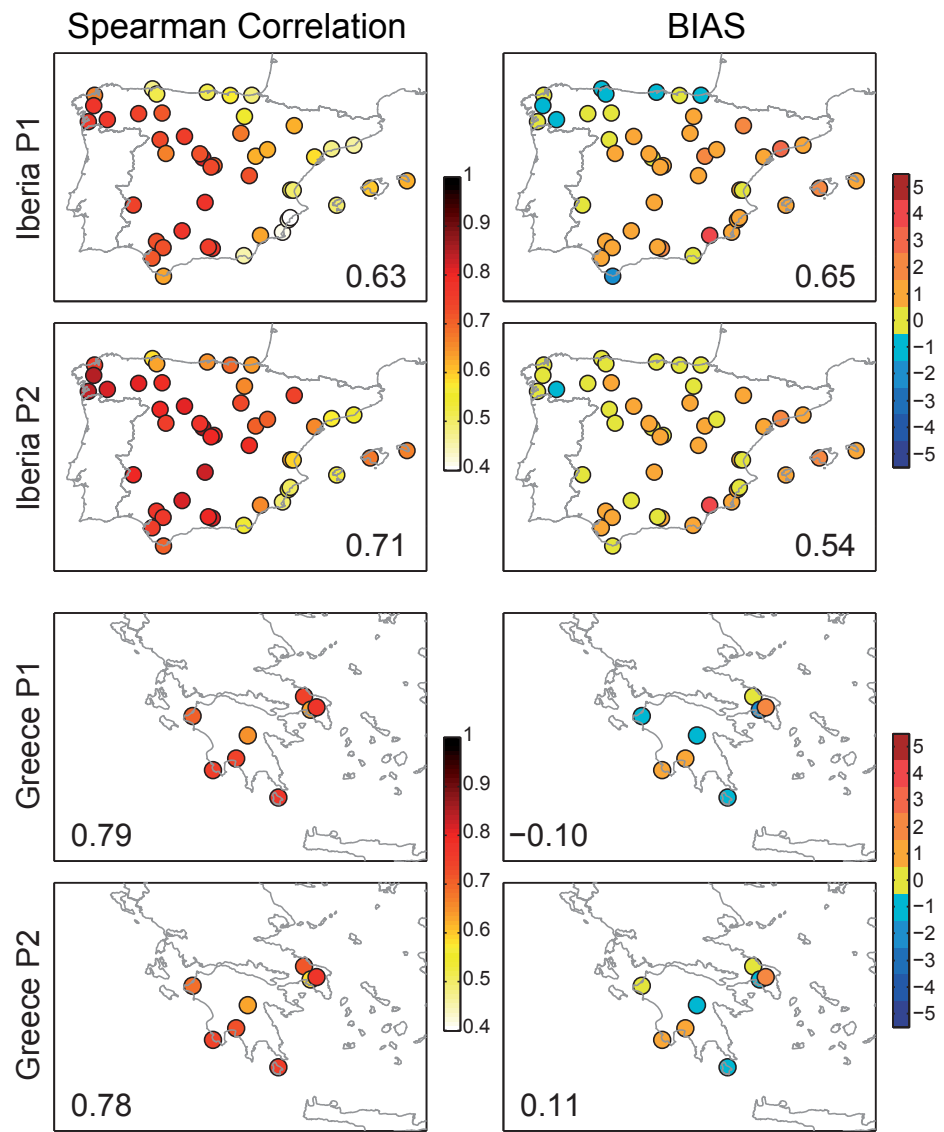

Fig. 4 Spearman correlation and bias between the observations and the downscaled FWI projections using two predictor combinations. Figures on each panel indicate the corresponding spatial mean values.

\section{Results in Perfect Model Conditions}

We applied the above described downscaling method to the four input meteorological variables, calculating the downscaled FWI values from the resulting downscaled inputs. First, we analyzed the performance of the method in perfect model conditions, so we downscaled the reanalysis data used for calibration within the same 
calibration period. In this case, some form of cross validation is necessary, since the same dataset is used for calibrating and testing the model. In particular we considered a k-fold cross-validation approach for the 25-year calibration period, using $k=5$ different combinations of calibration and test periods, each containing 20 years for calibration and 5 years for testing. We considered a stratified regular sampling, where the first test sample was formed by the years: 1979, 1984, 1989, 1994, 1999, the second by the years 1980, 1985, etc. (see e.g. Gutiérrez et al, 2013, for more details). The resulting five test periods cover the whole validation period (1979-2003), so they were concatenated into a single final test series which was used to compute the different validation scores.

In order to assess the predictive performance of the downscaling, the Spearman rank correlation coefficient was used as association measure between the observed and the predicted series. As opposite to the Pearson correlation, it is robust to outlier values and can deal with possible non-linear relationships between downscaled and observed time series. Hence, it is the preferable association measure for the different components of the FWI system and the rest of variables analyzed. The results obtained with the two predictor sets, P1 and P2, in terms of the Spearman correlation and bias, are shown in Fig. 4 for Iberia and Greece. This figure shows that the results for the benchmarking pattern P2 are slightly better than P1 in Iberia, whereas they perform similarly in Greece. Therefore, P1 seems to be a good pattern both in terms of skill and GCM reproducibility for downscaling climate change projections.

In order to further analyze the performance of the analog downscaling method, correlations for the daily and JJAS-averaged series were obtained for the P1 pattern (see Table 3 ). Results are shown for the different components of the FWI (see Section 2.2 for details) and for its input meteorological variables. In general, the method performs adequately considering the annual daily time series, which is the native time resolution of FWI, for the two study regions. However, not all input FWI variables are downscaled with the same skill, and the relatively high performance of the method for temperature and relative humidity contrasts with the poor correlations attained in the case of wind, and to a lesser extent, precipitation (the latter attaining better results in Greece than in Iberia). This fact has an effect on the resulting FWI components: For instance, components tracking fire spread, more directly dependent on wind (like ISI, see e.g. Wotton, 2009, for details), are less accurately predicted than components that predominantly rely in relative humidity and/or temperature (e.g. DMC and DC), although these are still dependent to some extent on precipitation. As depicted in Table 3, the performance of the analog downscaling decreases notably when considering the cross-correlations of averaged JJAS data. This is explained by the lower variability of the fire danger indices during the summer, that maintain high values due to the scarce precipitation and the high temperatures. In contrast, when computing the correlations with the annual daily series, the method is able to properly capture the seasonal cycle yielding better results. In consequence, performing the downscaling on the whole annual series is the recommended approach. 


\begin{tabular}{llccc|ccc}
\hline & & \multicolumn{3}{c|}{ IBERIA } & \multicolumn{3}{c}{ GREECE } \\
& & min & mean & max & min & mean & max \\
\hline \multirow{2}{*}{ WSS } & daily & 0.16 & 0.27 & 0.38 & 0.20 & 0.29 & 0.34 \\
& JJAS & -0.35 & 0.12 & 0.48 & -0.22 & 0.14 & 0.63 \\
\hline \multirow{2}{*}{ HURS } & daily & 0.22 & 0.51 & 0.72 & 0.23 & 0.53 & 0.68 \\
& JJAS & -0.24 & 0.30 & 0.67 & 0.09 & 0.42 & 0.61 \\
\hline \multirow{2}{*}{ PR } & daily & 0.23 & 0.35 & 0.53 & 0.37 & 0.49 & 0.55 \\
& JJAS & -0.21 & 0.21 & 0.50 & 0.23 & 0.42 & 0.60 \\
\hline \multirow{2}{*}{ TAS } & daily & 0.79 & 0.89 & 0.92 & 0.92 & 0.93 & 0.94 \\
& JJAS & 0.27 & 0.79 & 0.93 & 0.65 & 0.84 & 0.93 \\
\hline \multirow{2}{*}{ FFMC } & daily & 0.37 & 0.64 & 0.82 & 0.62 & 0.78 & 0.83 \\
& JJAS & -0.17 & 0.37 & 0.68 & 0.45 & 0.58 & 0.69 \\
\hline \multirow{2}{*}{ DMC } & daily & 0.61 & 0.80 & 0.90 & 0.82 & 0.89 & 0.93 \\
& JJAS & -0.16 & 0.28 & 0.66 & -0.26 & 0.31 & 0.62 \\
\hline \multirow{2}{*}{ DC } & daily & 0.33 & 0.67 & 0.89 & 0.57 & 0.81 & 0.91 \\
& JJAS & -0.43 & 0.23 & 0.56 & -0.26 & 0.28 & 0.47 \\
\hline \multirow{2}{*}{ ISI } & daily & 0.32 & 0.54 & 0.79 & 0.49 & 0.65 & 0.74 \\
& JJAS & -0.20 & 0.28 & 0.71 & 0.21 & 0.35 & 0.47 \\
\hline \multirow{2}{*}{ BUI } & daily & 0.58 & 0.80 & 0.90 & 0.81 & 0.89 & 0.93 \\
& JJAS & -0.28 & 0.27 & 0.62 & -0.29 & 0.33 & 0.75 \\
\hline \multirow{2}{*}{ FWI } & daily & 0.41 & 0.63 & 0.82 & 0.71 & 0.79 & 0.83 \\
& JJAS & -0.14 & 0.31 & 0.64 & 0.10 & 0.44 & 0.59 \\
\hline
\end{tabular}

Table 3 Results of cross-validation in terms of Spearman's rho obtained by the daily and seasonally (JJAS) averaged downscaled series, using the variables of the static atmospheric pattern $\mathrm{P} 1$ at $00 \mathrm{UTC}$.

\section{Climate Projections and Comparison with RCM Results}

Using the GCM variables, we computed FWI projections for the 20C3M scenario (for the control period 1971-2000) and for the transient A1B scenario (for the $21^{\text {st }}$ century). We first evaluated the performance of the downscaling method in the control period, considering the predictors from the $20 \mathrm{C} 3 \mathrm{M}$ scenario and using the period overlapping with the ERA-Interim reanalysis (1979-2000) to compare the results. Note that, as opposite to the downscaled series from the reanalysis, in this case there is no day-to-day correspondence between the model outputs and the observations, even though the projections are done in an historical period. Therefore, we just compared the climatological downscaled and observed values for the annual and the seasonal JJAS series, displaying also the results in perfect model conditions for comparison (Table 4). We found moderate biases in both the mean and standard deviation in the 20C3M scenario, with similar magnitudes to that corresponding to the reanalysis ones, and even smaller in some cases. In general, relative GCM biases are below $10 \%$ with some exceptions, particularly in the JJAS precipitation in Greece, with relatives biases both in the mean and the standard deviation larger than $20 \%$. However, the mean JJAS precipitation in Greece is small ( $0.37 \mathrm{~mm} /$ day vs. the 0.48 obtained with the downscaling method) and, hence, the relative errors are not very informative in this case.

Once verified that the GCM outputs are suitable for the statistical downscaling method, we proceeded with the calculation of the FWI increments/deltas for three different future periods: 2011-2040, 2041-2070 and 2071-2100. The deltas have been obtained as the period-averaged differences from the A1B and the 20C3M downscaled values. The results for JJAS are shown in Fig. 5 for SSR 
Table 4 Relative errors of the mean $\mu$ and standard deviation $\sigma$ climatological values of the downscaled w.r.t. the observed values (pred/obs - 1 in \%) according to pattern P1 (see Table 2) for ERA-Interim reanalysis (REA) and the ECHAM5 20C3M control scenario (CTL). Results correspond to the primitive FWI variables: temperature $(\mathrm{T})$, relative humidity $(\mathrm{H})$, precipitation $(\mathrm{P})$ and wind velocity $(\mathrm{W})$, and also to the resulting Fire Weather Index (FWI).

\begin{tabular}{llrr|rr||rr|rr}
\hline & \multicolumn{4}{c||}{ IBERIA } & \multicolumn{4}{c}{ GREECE } \\
\hline & & \multicolumn{2}{c}{ Annual } & \multicolumn{2}{c||}{ JJAS } & \multicolumn{2}{c}{ Annual } & \multicolumn{2}{c}{ JJAS } \\
& & $R E A$ & $C T L$ & $R E A$ & $C T L$ & $R E A$ & $C T L$ & $R E A$ & $C T L$ \\
\hline \multirow{2}{*}{$\mathrm{T}$} & $\mu$ & 0.1 & 1.1 & -0.5 & -0.1 & 0.2 & 0.5 & -0.2 & -0.5 \\
& $\sigma$ & -1.9 & -0.9 & 0.8 & 8.1 & -0.8 & -1.2 & -2.2 & 14.5 \\
\hline \multirow{2}{*}{$\mathrm{H}$} & $\mu$ & -0.4 & -1.0 & 0.5 & -0.9 & 0.7 & -1.0 & 0.6 & 0.0 \\
& $\sigma$ & -2.0 & -0.1 & -1.5 & 0.6 & 0.8 & 2.5 & -0.7 & 10.9 \\
\hline \multirow{2}{*}{$\mathrm{P}$} & $\mu$ & -8.8 & -0.6 & 0.0 & 1.1 & -0.6 & -4.9 & -2.7 & 29.7 \\
& $\sigma$ & -8.6 & -2.8 & -9.3 & -10.4 & -0.3 & -4.7 & 1.5 & 21.4 \\
\hline \multirow{2}{*}{$\mathrm{W}$} & $\mu$ & 0.1 & 2.1 & -1.1 & 0.6 & -1.9 & 3.7 & -1.8 & 2.3 \\
& $\sigma$ & -1.8 & -0.3 & -2.3 & -0.6 & -2.1 & 3.6 & -1.4 & 3.8 \\
\hline \multirow{2}{*}{ FWI } & $\mu$ & 2.6 & 3.4 & 0.6 & 2.7 & -4.2 & 1.9 & 9.9 & 12.5 \\
& $\sigma$ & -4.1 & -1.5 & -5.3 & -4.2 & 4.1 & 11.4 & -6.2 & 5.8 \\
\hline \hline
\end{tabular}

and FWI90 (columns 2 and 4). In both regions and for both indices, the deltas obtained with the analog method exhibit a similar pattern for the first two periods considered. The projected anomalies are larger for the FWI90, representing extreme fire danger conditions, than for SSR, representative of average conditions. Note that this is in accordance with recent results on the projected changes in climate extremes (Seneviratne et al, 2012). However, in the last period (2071-2100), the spatial pattern of these deltas is not consistent anymore, pointing to problems with the method. In this case, deltas show an unrealistic spatial variability, particularly for Greece, with big and small increments depending on the location; this may be the result of the complex interaction of the deltas for the four variables forming the FWI and is also an indication of the lack of robustness of the analog method in the period 2071-2100.

In order to check the consistency of the analog method with a dynamical downscaling model output, specially for the 2071-2100 period, we compared the performance of the statistical approach with the results of a dynamical downscaling. To this aim, we considered data from the state-of-the-art regional climate change projections in Europe provided by the ENSEMBLES project (van der Linden and Mitchell, 2009). In particular we used the RACMO2 RCM simulations (van Meijgaard et al, 2008), ran in the Royal Netherlands Meteorological Institute. This RCM was deemed the most appropriate in this study for several reasons: First of all, the driving GCM is the same as the one used for the statistical downscaling (ECHAM5, run 3), and thus the uncertainty linked to GCM projections in the final results can be ruled-out. Secondly, instantaneous noon data from this RCM are available in this case, needed for the calculation of the appropriate FWI scenarios. It must be noted that the publicly available ENSEMBLES database does not provide this type of data, but daily mean values instead, that should not be used for FWI calculation (Herrera et al, In press). Furthermore, the good performance of this GCM/RCM coupling has been reported in different studies (e.g., in the Iberian Peninsula by Herrera et al, 2010). 

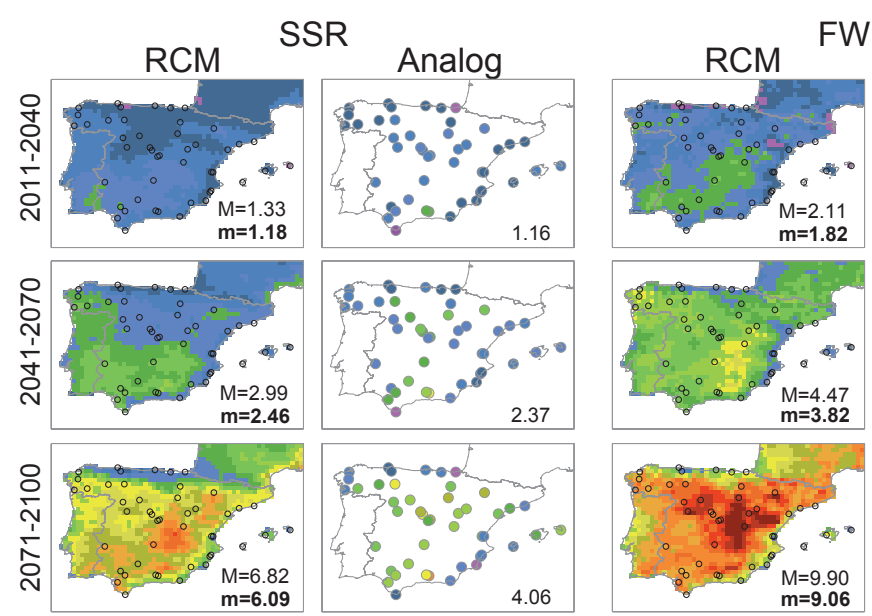

FWI90
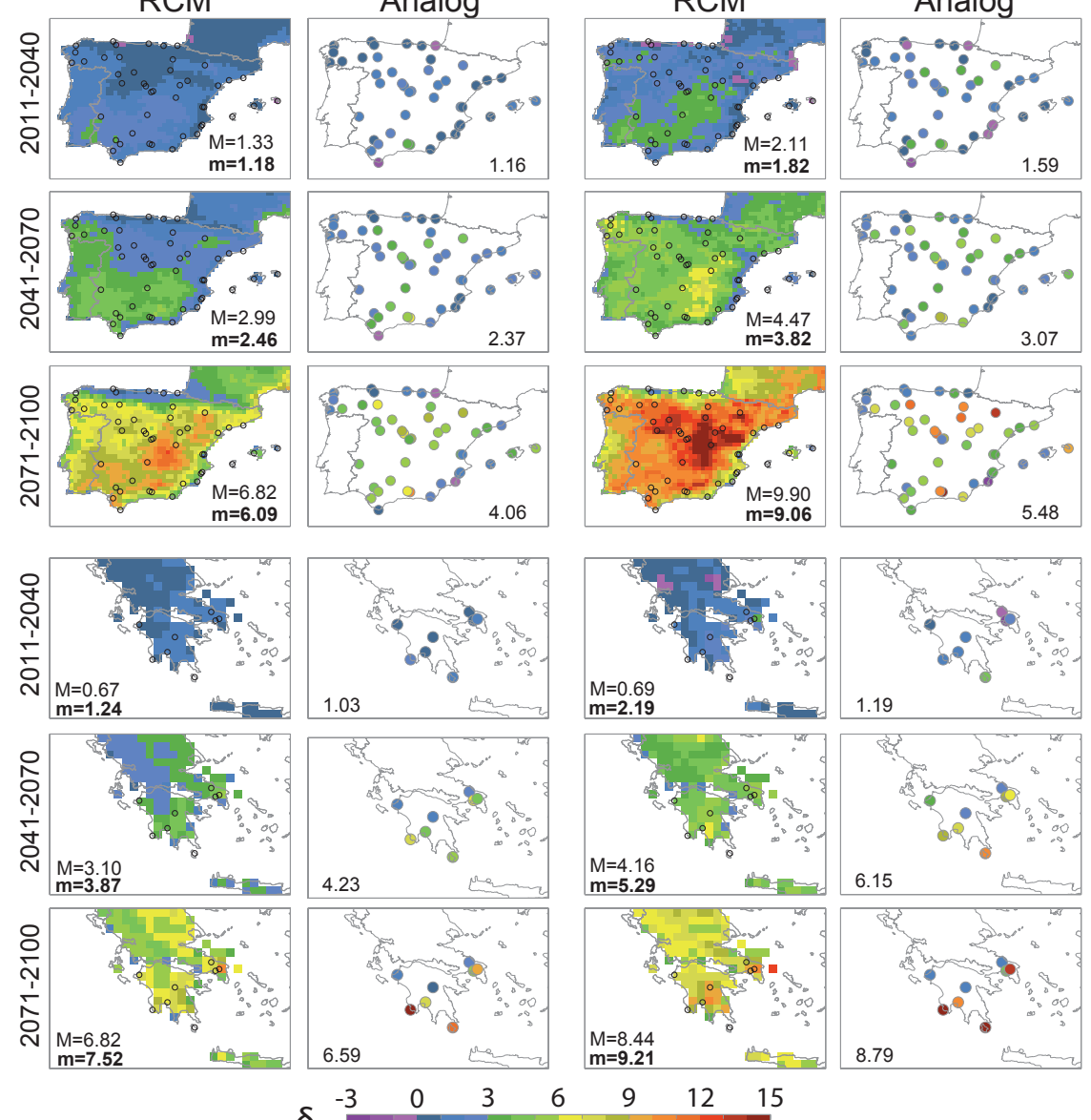

$\delta$

Fig. 5 Projected future fire regimes (A1B scenario) in terms of anomaly (delta) w.r.t. the control 20C3M scenario (1971-2000) for the periods 2011-2040, 2041-2070 and 2071-2100. Spatial mean values are indicated at the bottom of each panel. In the case of the RCM projections the spatial mean of the whole domain is indicated by the capital $M$ and the mean at the point locations by $m$. Fire danger indicators are seasonal severity rating (SSR) and 90th percentile of FWI (FWI90), both considered on the fire danger season (JJAS).

The resulting deltas of the RCM are shown in Fig. 5 (columns 1 and 3), which can be compared to the deltas obtained by the analog method for the same periods at the coincident grid cells. These results show that the spatial patterns and magnitudes of the climate change signal obtained using the analog method is comparable to that obtained by the RCM simulations for the first two future periods considered (2011-40 and 2041-70), and only in the last decades of $21^{\text {st }}$ century (2071-2100) a departure between both types of projections becomes evident, with a tendency of the statistical method to underestimate the climate change signal compared to the RCM. For the case of Iberia, this issue is further illustrated in Fig. 6, which shows the point-based values of the statistical downscaling method 

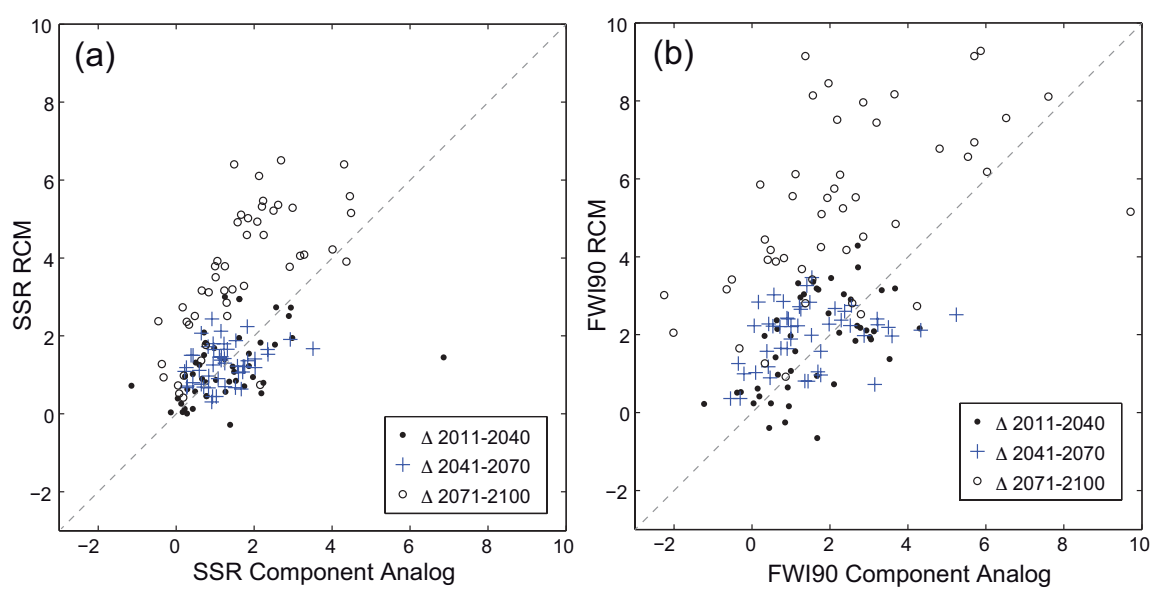

Fig. 6 Climate change signals (deltas) for the three future periods (2011-2040, 2042-2070 and 2071-2100) at the point locations in Iberia for a) the seasonal severity rating (SSR) and b) 90th percentile of FWI (FWI90), according to the statistical downscaling method (X-axis) and the dynamical downscaling projections of the RCM (Y-axis).

versus the RCM ones in the corresponding nearest grid-boxes. This result is in agreement with previous findings reporting the lack of robustness of the analog method in non stationary conditions for some of the variables involved (see e.g. Gutiérrez et al, 2013). On the other hand, RCMs have been shown to over-estimate temperature and dryness in the last decades of $21^{\text {st }}$ century (Christensen et al, 2008; Maraun, 2012), thus possibly inflating fire danger projections. Therefore this departure between dynamical and statistical projections accounts not only for limitations of the analog method, but also to known problems of dynamical downscaling methods.

\section{Conclusions}

The performance of the analog method to project Fire Weather Index from global model outputs was assessed in the Iberian Peninsula and Greece. The analog method is adequate in order to preserve the physical coherence between all variables involved in FWI calculation, but problems due to the inability of the method to extrapolate variable magnitudes beyond the historical records, may limit its applicability when projecting future climate scenarios. Overall, the analog method produced good results when applied in perfect model conditions, although not with equal success for the four FWI input variables. The method exhibited a high skill for temperature and relative humidity, and worse results in the case of precipitation and especially wind, limiting the performance of the components of the FWI more dependent on these variables. However, these deficiencies are compensated in the resulting FWI values due to the overall high performance of temperature and relative humidity, which have been shown to be the most influential variables on FWI (Bedia et al, 2012). 
Our results also reveal that the downscaling method presented is able to properly reproduce the fire danger regimes of the 25-year historical period considered, both the mean fire danger conditions, as represented by the SSR, and the extreme fire danger conditions, defined by the FWI90. However, due to the nature of the analog method, the downscaled series do not preserve the daily temporal sequencing of the different FWI codes tracking drought and fuel moisture, and thus caution must be taken in the eventual case of day-to-day analyses.

To date, this is the first study showing that statistical downscaling can be successfully applied for the generation of local future fire danger scenarios, attaining comparable results to RCM projections. This holds true until the last part of the transient period (2071-2100 in this study), when problems stemming from non-stationarities negatively affect to both methodologies: On the one hand, at this point the analog method starts suffering from a lack of robustness as unprecedent warm days become increasingly frequent. This is manifested by a spatially inhomogeneous pattern of the resulting anomalies, not corresponding with the pattern obtained using the RCM. On the other hand, in this later period RCMs are known to overestimate summer temperatures and dryness, thus leading to inflated fire danger projections. Therefore, we advocate caution on the use of projections for the last decades of the $21^{\text {st }}$ century in climate impact studies, regardless of the regionalization technique applied.

Acknowledgements We are grateful to the Spanish Meteorological Agency (AEMET) and to the Hellenic National Meteorological Service (HNMS) for providing the observational data used in this study. We would also like to thank Erik van Meijgaard from the Royal Netherlands Meteorological Institute for making available ENSEMBLES RACMO2 climate model output verifying at 12:00 UTC and to the Max Planck Institute for providing the appropriate data for the ECHAM5 model used in this work. This work was partly funded by European Union's Seventh Framework Programme (FP7/2007-2013) under grant agreements 243888 (FUME Project) and from Spanish Ministry MICINN under grant EXTREMBLES (CGL2010-21869). We thank two anonymous referees for their useful comments that helped to improve the original manuscript.

\section{References}

Abatzoglou J, Brown T (2012) A comparison of statistical downscaling methods suited for wildfire applications. Int J Climatol 32:772-780, DOI 10.1002/joc.2312

Andrews P, Loftsgaarden D, Bradshaw L (2003) Evaluation of fire danger rating indexes using logistic regression and percentile analysis. Int $\mathrm{J}$ Wildland Fire $12: 213-226$

Bedia J, Herrera S, Gutiérrez J, Zavala G, Urbieta I, Moreno J (2012) Sensitivity of Fire Weather Index to different reanalysis products in the Iberian Peninsula. Nat Hazards Earth Syst Sci 12:699-708, DOI 10.5194/nhess-12-699-2012

Benestad RE (2010) Downscaling precipitation extremes. Theoretical and Applied Climatology 100:1-21, DOI \{10.1007/s00704-009-0158-1\}

Benestad RE, Hanssen-Bauer I, Chen D (2008) Empirical-Statistical Downscaling, 1st edn. World Scientific Publishing, Singapore

Brands S, Herrera S, San-Martín D, Gutiérrez J (2011) Validation of the ENSEMBLES Global Climate Models over southwestern Europe using probability density functions: A downscaler's perspective. Climate Research 48:145-161, DOI $10.3354 /$ cr00995 
Brown T, Hall B, Westerling A (2004) The impact of twenty-first century climate change on wildland fire danger in the westerns United States: An applications perspective. Clim Change 62:365-388

Camia A, Amatulli G, San Miguel-Ayanz J (2008) Past and future trends of forest fire danger in Europe. Tech. Rep. EUR 23427 EN - 2008, Institute for Environment and Sustainability, Joint Research Centre, European Comission, Ispra, Italy

Christensen J, Boberg F, Christensen O, Lucas-Picher P (2008) On the need for bias correction of regional climate change projections of temperature and precipitation. Geophysical Research Letters 35:L20,709, DOI \{10.1029/ 2008GL035694\}

Cubasch U, vonStorch H, Waszkewitz J, Zorita E (1996) Estimates of climate change in Southern Europe derived from dynamical climate model output. Climate Research 7:129-149

Dee DP, Uppala SM, Simmons AJ, Berrisford P, Poli P, Kobayashi S, Andrae U, Balmaseda MA, Balsamo G, Bauer P, Bechtold P, Beljaars ACM, van de Berg L, Bidlot J, Bormann N, Delsol C, Dragani R, Fuentes M, Geer AJ, Haimberger L, Healy SB, Hersbach H, Hólm EV, Isaksen L, Kållberg P, Köhler M, Matricardi M, McNally AP, Monge-Sanz BM, Morcrette J, Park B, Peubey C, de Rosnay P, Tavolato C, Thépaut JN, Vitart F (2011) The ERA-Interim reanalysis: configuration and performance of the data assimilation system. Quart J R Meteorol Soc (137):553-597

Dimitrakopoulos A, Bemmerzouk A, Mitsopoulos I (2011) Evaluation of the Canadian fire weather index system in an eastern Mediterranean environment. Meteorol Appl 18:83-93

Dowdy A, Mills G, Finkele K, deGroot W (2010) Index sensitivity analysis applied to the Canadian Forest Fire Weather Index and the McArthur Forest Fire Danger Index. Meteorol Appl 17:298-312

Flannigan M, Logan K, Amiro B, Skinner W, Stocks B (2005) Future area burned in Canada. Clim Change 72(1-2):1-16, DOI 10.1007/s10584-005-5935-y

Giorgi F, Lionello P (2008) Climate change projections for the Mediterranean region. Global and Planetary Change 63:90-104, DOI 10.1016/j.gloplacha.2007. 09.005

Giorgi F, Mearns LO (1999) Introduction to special section: Regional climate modeling revisited. Journal of Geophysical Research 104:6335-6352

Groisman PY, Sherstyukov BG, Razuvaev VN, Knight RW, Enloe JG, Stroumentova NS, Whitfield PH, Forland E, Hannsen-Bauer I, Tuomenvirta H, Aleksandersson H, Mescherskaya AV, Karl TR (2007) Potential forest fire danger over Northern Eurasia: Changes during the 20th century. Global and Planetary Change 56:371-386, DOI \{10.1016/j.gloplacha.2006.07.029\}

Gutiérrez J M, Ribalaygua J, Llasat C, Romero R, Abaurrea J, Rodríguez-Camino E (2012) Cambio climático: Extremos e Impactos. Publicaciones de la Asociación Española de Climatología (AEC). Serie A, 8:125-135

Gutiérrez J, San-Martín D, Brands S, Manzanas R, Herrera S (2012) Reassessing statistical downscaling techniques for their robust application under climate change conditions. Journal of Climate DOI \{10.1175/JCLI-D-11-00687.1\}

Herrera S, Fita L, Fernández J, Gutiérrez J (2010) Evaluation of the mean and extreme precipitation regimes from the ENSEMBLES regional climate multimodel simulations over Spain. J Geophys Res 115, DOI \{10.1029/2010JD013936\} 
Herrera S, Bedia J, Gutiérrez J, Fernández J, M MJ (In press) On the projection of future fire danger conditions with various instantaneous/mean-daily data sources. Climatic Change

Imbert A, Benestad R (2005) An improvement of analog model strategy for more reliable local climate change scenarios. Theoretical and Applied Climatology 82:245-255, DOI $\{10.1007 /$ s00704-005-0133-4 $\}$

Koutsias N, Arianoutsou M, Kallimanis A, Mallinis G, Halley J, Dimopoulos P (2012) Where did the fires burn in Peloponnisos, Greece the summer of 2007 ? Evidence for a synergy of fuel and weather. Agr Forest Meteorol 156:41-53

Krawchuk M, Cumming S, Flannigan M (2009) Predicted changes in fire weather suggest increases in lightning fire initiation and future area burned in the mixedwood boreal forest. Clim Change 92:83-97, DOI 10.1007/s10584-008-9460-7

Lawrence M (2005) The Relationship between Relative Humidity and the Dewpoint Temperature in Moist Air. A Simple Conversion and Applications. Bulletin of the American Meteorological Society pp 225-233, DOI 10.1175/ BAMS-86-2-225

Lorenz E (1963) Deterministic nonperiodic flow. Journal of the Atmospheric Sciences 20:130-141

Lorenz E (1969) Atmospheric predictability as revealed by naturally occurring analogues. Journal of the Atmospheric Sciences 26:636-\&

Maraun D, Wetterhall F, Ireson A M, Chandler R E, Kendon E J, Widmann M, Brienen S, Rust H W, Sauter T, Themessl M, Venema V K C, Chun K P, Goodess C M, Jones R G, Onof C, Vrac M, Thiele-Eich I (2010) Precipitation Downscaling under Climate Change: Recent Developments to Bridge the Gap Between Dynamical Downscaling Models and the End User. Reviews of Geophysics 48:RG3003, DOI \{10.1029/2009RG000314\}

Maraun D (2012) Nonstationarities of regional climate model biases in European seasonal mean temperature and precipitation sums. Geophysical Research Letters 39:L06,706, DOI $\{10.1029 / 2012$ GL051210 $\}$

Meyn A, White P, Buhk C, Jentsch A (2007) Environmental drivers of large, infrequent wildfires: The emerging conceptual model. Progress in Physical Geography 31:287-312

Meyn A, Schmidtlein S, Taylor SW, Girardin MP, Thonicke K, Cramer W (2010) Spatial variation of trends in wildfire and summer drought in British Columbia, Canada, 1920-2000. International Journal of Wildland Fire 19:272-283, DOI $\{10.1071 /$ WF 09055$\}$

Moriondo M, Good P, Durao R, Bindi M, Giannakopoulos C, Corte-Real J (2006) Potential impact of climate change on fire risk in the mediterranean area. Clim Res 31:85-95

Palheiro P M, Fernandes P, Cruz M G (2006) A fire behaviour-based fire danger classification for maritime pine stands: Comparison of two approaches. Forest Ecology Management (-):234S-S54

Pausas J (2004) Changes in fire and climate in the eastern Iberian Peninsula (Mediterranean basin). Climatic Change 63:337-350

Pechony O, Shindell DT (2010) Driving forces of global wildfires over the past millennium and the forthcoming century. P Natl Acad Sci USA 107(45):19,16719,170, DOI \{10.1073/pnas.1003669107\}

Räisänen J (2007) How reliable are climate models? Tellus A 59:2-29 
Seneviratne S, Nicholls N, Easterling D, Goodess C, Kanae S, Kossin J, Luo Y, Marengo J, McInnes K, Rahimi M, Reichstein M, Sorteberg A, Vera C, Zhang $\mathrm{X}$ (2012) Changes in climate extremes and their impacts on the natural physical environment. In: Field C, Barros V, Stocker T, Qin D, Dokken D, Ebi K, Mastrandrea M, Mach K, Plattner GK, Allen S, Tignor M, Midgley P (eds) Managing the Risks of Extreme Events and Disasters to Advance Climate Change Adaptation, Cambridge University Press, Cambridge, UK, and New York, USA, pp 109-230

Stocks B, Fosberg M, Lynham T, Mearns L, Wotton B, Yang Q, Jin JZ, Lawrence K, Hartley G, Mason J, McKenney D (1998) Climate change and forest fire potential in Russian and Canadian boreal forests. Clim Change 38:1-13

Turco M, Llasat M, von Hardenberg J, Provenzale A (2012) Impact of climate variability on summer fires in a Mediterranean environment (northeastern Iberian Peninsula). Climatic Change DOI 10.1007/s10584-012-0505-6

Uppala SM, Kallberg PW, Simmons AJ, Andrae U, Bechtold VD, Fiorino M, Gibson JK, Haseler J, Hernandez A, Kelly GA, Li X, Onogi K, Saarinen S, Sokka N, Allan RP, Andersson E, Arpe K, Balmaseda MA, Beljaars ACM, Van De Berg L, Bidlot J, Bormann N, Caires S, Chevallier F, Dethof A, Dragosavac M, Fisher M, Fuentes M, Hagemann S, Holm E, Hoskins BJ, Isaksen L, Janssen PAEM, Jenne R, McNally AP, Mahfouf JF, Morcrette JJ, Rayner NA, Saunders RW, Simon P, Sterl A, Trenberth KE, Untch A, Vasiljevic D, Viterbo P, Woollen J (2012)The ERA-40 re-analysis. Q. J. R. Meteorol. Soc.131(612, Part b):29613012

van der Linden P, Mitchell J (2009) ENSEMBLES: Climate change and its impacts: Summary of research and results from the ENSEMBLES project. Tech. rep., Met Office Hadley Centre, Exeter, UK

van Meijgaard E, van Ulft L, van de Berg W, Bosveld F, van den Hurk B, Lenderink G, Siebesma A (2008) The KNMI regional atmospheric climate model RACMO, version 2.1. Tech. Rep. 302, R. Neth. Meteorol. Inst., De Bilt, Netherlands

Viegas D, Bovio G, Ferreira A, Nosenzo A, Sol B (1999) Comparative study of various methods of fire danger evaluation in southern Europe. Int J Wildland Fire 9:235-246

van Wagner CE (1970) Conversion of William's Severity Rating for use with the Fire Weather Index. Information Report PS-X-21, Canadian Forestry Service, Ontario, Canada

van Wagner CE (1987) Development and structure of the Canadian Forest Fire Weather Index. Forestry Tech. Rep. 35, Canadian Forestry Service, Ottawa, Canada

van Wagner CE, Pickett TL (1985) Equations and FORTRAN program for the Canadian forest fire weather index system. Forestry Tech. Rep. 33, Canadian Forestry Service, Ottawa, Canada

Wotton BM (2009) Interpreting and using outputs from the Canadian Forest Fire Danger Rating System in research applications. Environ Ecol Stat 16:107-131, DOI 10.1007/s10651-007-0084-2

Zorita E, von Storch H (1999) The analog method as a simple statistical downscaling technique: Comparison with more complicated methods. Journal of Climate 12:2474-2489

Zorita E, Hughes J, Lettemaier D, Von Storch H (1995) Stochastic characterization of regional circulation patterns for climate model diagnosis and estimation of 
local precipitation. Journal of Climate 8:1023-1042 